\title{
Validating gameplay activity inventory (GAIN) for modeling player profiles
}

\author{
Jukka Vahlo $^{1,2}$ (D) Jouni Smed ${ }^{3}$ (D) Aki Koponen ${ }^{4}$
}

Received: 30 January 2018 / Accepted in revised form: 1 November 2018 / Published online: 13 November 2018 (c) The Author(s) 2018

\begin{abstract}
In the present study, we validated Gameplay Activity Inventory (GAIN), a short and psychometrically sound instrument for measuring players' gameplay preferences and modeling player profiles. In Study 1 , participants in Finland $(N=879)$ responded to a 52-item version of GAIN. An exploratory factor analysis was used to identify five latent factors of gameplay activity appreciation: Aggression, Management, Exploration, Coordination, and Caretaking. In Study 2, respondents in Canada $(N=1322)$ and Japan $(N=1178)$ responded to GAIN, and the factor structure of a 15 -item version was examined using a Confirmatory Factor Analysis. The results showed that the short version of GAIN has good construct validity, convergent validity, and discriminant validity in Japan and in Canada. We demonstrated the usefulness of GAIN by conducting a cluster analysis to identify player types that differ in both demographics and game choice. GAIN can be used in research as a tool for investigating player profiles. Game companies, publishers and analysts can utilize GAIN in player-centric game development and targeted marketing and in generating personalized game recommendations.
\end{abstract}

Keywords Digital games $\cdot$ Media choice $\cdot$ Player profiles $\cdot$ Confirmatory factor analysis $\cdot$ Scale development $\cdot$ Scale validation

\footnotetext{
$凶$ Jukka Vahlo

jukka.vahlo@utu.fi

Jouni Smed

jouni.smed@utu.fi

Aki Koponen

aki.koponen@utu.fi

1 Centre for Collaborative Research, Turku School of Economics, University of Turku, Turku, Finland

2 Game Research Lab and Gamification Group, Tampere University, Tampere, Finland

3 Department of Future Technologies, University of Turku, Turku, Finland

4 Laboratory of Business Disruption Research, Turku School of Economics, University of Turku, Turku, Finland
} 


\section{Introduction}

The rise in popularity of digital games, ranging from console and PC video games to free-to-play mobile games and virtual reality games, calls for better tools for understanding what makes a gameplay experience gratifying to players and what factors are related to game preferences and choices in game consumption. According to some estimations, in 2016 more than 750,000 games were published across gaming platforms (Neogames 2016). Game marketplaces are saturated, and it has become very difficult for game companies and publishers to reach loyal paying customers, and for players to find the games that are the most enjoyable for them.

The objective of investigating preferences in playing digital games is closely related to discussions on game choice and, consequently, to applications of media choice theory. Identifying the factors that have an effect on game choice is an important task for efficient and targeted marketing. Player profiles can be utilized as a tool for identifying patterns in consumption behavior, and a successful player typology could therefore serve as beneficial for game companies and players alike.

Motivations to play and other psychographic segmentations (see Hartmann and Klimmt 2006; Hamari and Tuunanen 2014, p. 34), as well as player behavioral approaches, have been utilized in constructing player typologies and player personas, that is, representative players (Drachen et al. 2009; Vahlo and Koponen 2018). Player typologies based on behavior data (e.g., psychometric measurements, game logs, and telemetrics) aim to scrutinize patterns in dynamic gameplay interaction. These are approaches of player modeling. Studies on motivations to play are instead endeavors of player profiling, which analyze players' sustained game preferences that exist beyond any given act of gameplay (Yannakakis et al. 2013; Cowley and Charles 2016).

Motivations to play studies (e.g., Bateman et al. 2011; Przybylski et al. 2010; Sherry et al. 2006; Yee 2006) aim to track down the reasons why players play digital games in general, or why they favor a particular type of digital game, for example, online multiplayer games (Yee 2006; Yee et al. 2012). Behavioral approaches (e.g., Bartle 2003; Mulligan and Patrovsky 2003; Tseng 2010; Cowley and Charles 2016), on the other hand, ask how players play the game they have chosen to play. For instance, Bartle (1996, 2003) fashioned a player type model by analyzing multi-user dungeon (MUD) users' bulletin-board posts and classifying the players according to their preferred playing styles as achievers, explorers, socializers and killers.

However, neither studies on play motivations nor play behavior provide a sufficient approach for understanding which games players are likely to choose. Studies on motivations to play are very general, while player behavior models tend to be too specific in this regard. Recently, a third approach has been proposed for profiling players which could be used for predicting game choice. Vahlo et al. (2017) call this approach game preference research. Since the third approach aims to bring together characteristics of gameplay and players' sustained preferences for specific kinds of gameplay experiences, this approach can be situated in between player behavior and motivations to play models.

Considerable effort has been put into studies on motivations to play and player behavior, but identifying players' appreciation of various game dynamics has not been studied extensively. The current study focuses on this aspect of digital gaming and thus 
contributes to the understanding of players' preferences and habits in specific kinds of gameplay. Fleshing out players' preference profiles in gameplay appreciation is an important addition for player type research because it enables us to analyze continuities and emergent trends in gaming cultures in a way that may inform decision-making in game development and marketing.

The purpose of this study is to develop and validate a psychometrically sound short instrument for measuring players' gameplay activity preferences in contemporary digital games, and to demonstrate the potential of the instrument in constructing player profiles and in predicting game choice. The introduced Gameplay Activity Inventory (GAIN) is based on a theoretical model and on the Core Game Dynamics (CGD) scale presented by Vahlo et al. (2017). The original CGD scale is a 28 -item Likert7 measurement, which the authors (ibid.) argue consists of five latent factors. Their argument is based on an exploratory factor analysis (EFA) that the authors conducted with a data sample of 1718 respondents from Finland and Denmark. However, the fivefactor model of the CGD scale has not yet been validated. Furthermore, and as Vahlo et al. (2017) note, more items should be developed and included in the inventory. The inventory should also be balanced and shortened in order to make it more applicable to surveys. All of these shortcomings ought to be addressed before the model can be widely utilized for research purposes.

In this article, we investigate whether the five-factor structure of players' gameplay preferences can be validated and if the instrument can be shortened by conducting a Confirmatory Factor Analysis (CFA) on additional data sets. We begin by presenting our theoretical framework and research questions of the current study. Next, we analyze the Core Game Dynamics (CGD) scale as explored by Vahlo et al. (2017). We proceed to present a data triangulation for the items of the CGD scale by studying a total of 166 game instruction booklets. This is followed by an EFA for a reconsidered Gameplay Activity Inventory (GAIN) with a representative sample of 879 Finnish people. The rationale for another EFA is to screen the GAIN items and to build solid empirical grounds for a shorter and more robust inventory.

We continue then by describing our utilization of structural equation modelling (SEM) to construct a CFA for the argued-for five-factor model of gameplay activity preferences with representative data sets collected from Japan $(N=1178)$ and Canada $(N=1322)$. After investigating the construct validity, convergent validity, and discriminant validity of the shortened version of GAIN, we report a cluster analysis aimed at finding out whether player types could be identified by investigating players' preferences in the five gameplay activity factors. We continue then to explore the relationships between the identified player types and their habits to play games of specific genres. By doing so, we discuss how the findings provide new knowledge about which games players are likely to choose.

\section{Theoretical framework}

Vahlo et al. (2017) suggest that game dynamics or gameplay activities should be considered as a unit of analysis in game preference research (see also Tondello et al. 2017). In this study, we have chosen to use 'gameplay activity' over 'game dynamics' 
(cf. Vahlo et al. 2017), because the former concept is readily more comprehensible for players and game designers than the latter, which refers to how interrelated game mechanics (Sicart 2009) are experienced as an emergent whole during gameplay (LeBlanc 2004; Hunicke et al. 2004; Vahlo et al. 2017; Vahlo 2017).

Furthermore, gameplay challenges and gameplay activities can both be considered as constituents of game dynamics (see Vahlo et al. 2017; Adams 2014). A player may encounter strategic or tactical challenges in various kinds of gameplay activities, which may or may not be related to, for example, behavioral models, aesthetics and narrative representations of warfare. Similarly, a player may try to overcome challenges that require creative problem-solving skills in very different kinds of activities and fictional settings. Hence, if we were to operate with the concept of game dynamics, the distinction between activities and challenges would be more difficult to establish.

Gameplay challenges and gameplay activities thus refer to separate dimensions of the gameplay experience. Because challenge types are of a higher level of abstraction than activity types, we presume that it is more intuitive for players to reflect on their gameplay activity preferences than gameplay challenge type preferences. Because of these reasons, we have decided to focus only on gameplay activities and exclude gameplay challenge types from the scale development. Therefore, we have relabeled the CGD scale presented by Vahlo et al. (2017) as the Gameplay Activity Inventory (GAIN).

An approach based on investigating gameplay activity preferences is also related to media choice theory, which states that users' preferences are consistently and systematically connected to media content, and that users exemplify their preferences in the patterns of their media consumption (Webster and Wakshlag 1983; Scherer and Naab 2009). Next, we situate our approach to media choice theories, and move then to present the research questions of this study.

\subsection{Game choice}

Media choice, and consequently game choice, has been conceptualized in the literature from the perspectives of need satisfaction, motivations and gratification (e.g., Ruggiero 2000; Krcmar and Strizhakova 2009), moods (e.g., Vorderer et al. 2004), taste (e.g., Peterson 2005), and preference type (e.g., Youn 1994; Prior 2007) factors (see Webster 2011). We argue in this article that dynamical and structural characteristics and resources of game media constitute an important factor in identifying game choice. Our approach is consistent both with the Theory of Subjective Quality Assessment (TSQA) and the structuration theory (Webster 2009, 2011, 2014).

From a structuration theoretical viewpoint, there are three equally important constituents in media choice: agents, structures, and their duality or reciprocity (Webster 2011). Indeed, structuration approaches can be portrayed as audience-centric instead of media-centric or user-centric (Webster and Ksiasek 2012). The structuration theory differs in this regard from the uses and gratifications paradigm and from the mood management approach, both of which emphasize psychological factors in media choice (see e.g., Ruggiero 2000; Rubin 2002; Sherry 2004; Vorderer et al. 2004; Scherer and Naab 2009). A structural theoretical stance enables us to consider how media prod- 
ucts shape players' preference patterns, and how players' sustaining game choices influence what kinds of games are produced (Webster 2011; Jöckel and Dogruel 2012).

The model we present also draws from the Theory of Subjective Quality Assessment (TSQA). The TSQA argues that the media selections a person makes are guided by the implicit or explicit features and attributes of the perceived product, and of the desires of the user. In contrast to the uses and gratifications and mood management approaches, the TSQA is, in principle, able to track down the specific characteristics of a media product that have caused a user to experience gratification or inspired a preference change. However, the TSQA is akin to the uses and gratifications approach in its objective to explain long-term and medium-term patterns in media use (Wolling 2009).

In conducting research based on the TSQA, a crucial task is to identify which features of the products the users consider paramount for making quality assessments and value judgements (Wolling 2009, p. 88). Genre is an important factor in how a player's quality assessment transfers from one game product to another. It has been argued that individuals develop sustaining genre preferences as well as an individual taste in games in 'gaming socialization', that is, through experimentation and specialization (see Greenberg et al. 2010; von Salisch et al. 2011; Scharkow et al. 2015). Players' genre preferences have been discussed in previous research mostly from the perspective of gender (e.g., Lucas and Sherry 2004), age (e.g., De Schutter 2011; Quandt et al. 2009), or gratifications and motives (e.g., Hartmann and Klimmt 2006; Greenberg et al. 2010).

Prior research has argued that video game genres are primarily separated from each other based on the kinds of interactivity they afford for the player in gameplay challenges and activities (e.g., Apperley 2006; Arsenault 2009; Landay 2014). However, video game genres are emergent constructs: new subgenres are constantly introduced both by game companies and by player communities themselves (Arsenault 2009, 2014; Juul 2014; Clarke et al. 2015). Thus, it is more relevant to investigate which game design constituents (i.e. game mechanics and dynamics) players find attractive rather than operate with established game genre constructs in fashioning players TSQA criteria (Vahlo et al. 2017).

In the current structuration analytical and TSQA-inclined study, we associate 'structure' with the level of gameplay activities, which is enabled by interrelated game mechanics designed in games (Vahlo et al. 2017). Descriptions of gameplay activities are commonly used in both game journalism and player communities (Kirkpatrick 2012; Vahlo et al. 2017). In the TSQA it is contended that the elements of products to which people constantly refer in conversations form a plausible basis for modeling quality assessment criteria in media choice (Wolling 2009, p. 94).

As argued in activity theory (Kaptelinin and Nardi 2006), activities are purposeful, participatory and object-oriented. As with the agent-structure-duality approach in the structuration theory (Webster 2014), the concept of 'gameplay activity' manages thus to refer simultaneously to the motivated player-subject, to the dynamic game object, and to the reciprocity between these two constituents of the gameplay experience (Juul 2005, pp. 83-88; Björk and Holopainen 2006, p. 411; Leino 2012, pp. 58-59; Vahlo 2017). 


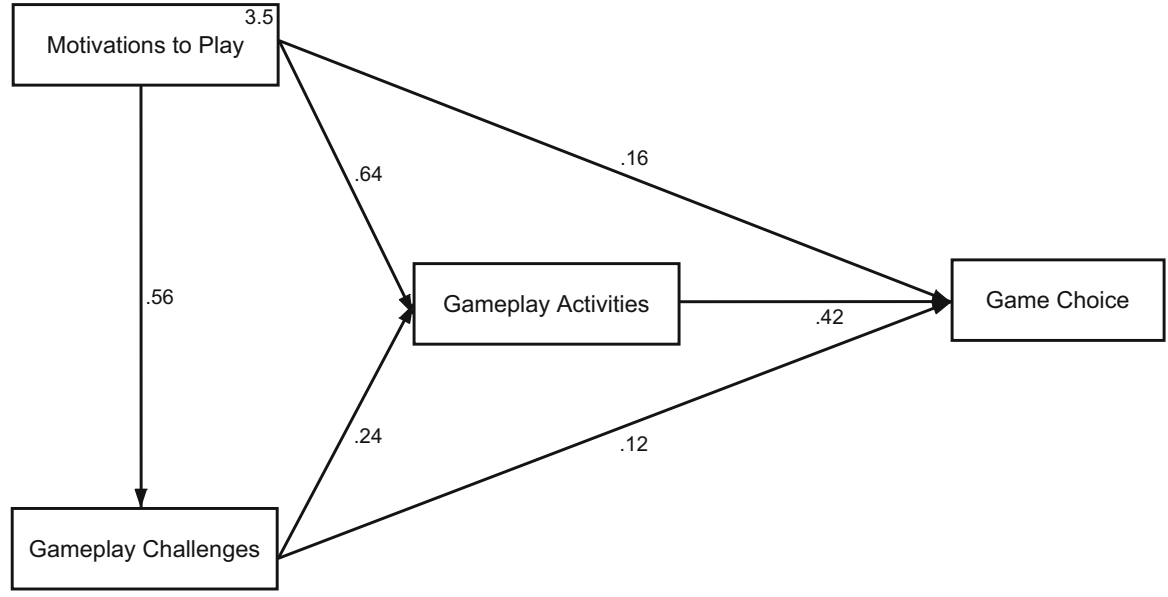

Fig. 1 A game choice prediction model $(\mathrm{N}=3551)$ as presented originally by Vahlo and Koponen (2018). The observed variables were constructed by calculating mean sums for each scale. All loading shown in the figure are significant on the level of $p<0.001$

\subsection{Research questions}

The original Core Game Dynamics (CGD) scale is a 28-item Likert-7 questionnaire in which respondents are asked to rate how pleasant recurrent digital game dynamicssuch as collecting rare items, managing cities, or exploding and destroying - are for them as players $(1=$ very unpleasant, $7=$ very pleasant). Vahlo et al. (2017) identified five latent constructs in the CGD scale by conducting an exploratory factor analysis (EFA) with data from 1718 respondents. They labeled the factors Assault, Manage, Journey, Coordinate, and Care. As specified by Vahlo et al. (2017), the next phase for the inventory is to further develop the survey items and conduct a theory-driven confirmatory analysis with a large data set representing cultural backgrounds other than Finnish and Danish. The first research question of this study can thus be summarized as:

RQ1 Can we confirm that players' gameplay activity preferences consist of five factors? If so, are these factors similar to the five factors presented by Vahlo et al. (2017)?

Vahlo and Koponen (2018) studied how being motivated to play, enjoying in-game challenges and in-game activities predict game choice. By analyzing the survey data from 3551 adult respondents, they constructed a SEM model for predicting game choice. This was done by studying the direct and indirect effects of gaming motivations, gameplay challenge appreciation, and gameplay activity preferences on game choice, as measured by survey participants' reported frequency to play digital games of different genres. Motivations to play were measured by a 25-item 5-point Likert scale, gameplay challenge appreciation by a 9-item 5-point Likert scale, and gameplay activity preferences by a 28-item 5-point Likert scale (Fig. 1).

In the study by Vahlo and Koponen (2018), being motivated to play and appreciating in-game challenges predicted weakly game choice (i.e., a habit of playing a variety of digital game genres). In comparison, the effect of gameplay activity preference on game choice was moderate. Indeed, although motivations to play had the largest total 
effect on game choice, this effect was mostly indirect, which indicates that predictions of players' game choices should be based primarily on gameplay activity preference profiling and modeling. Furthermore, as argued in the TSQA (Wolling 2009), users evaluate and choose media products based on readily observable qualities and features. In contrast to gameplay activities, gameplay challenges are abstract constructs, which, consequently, are not as commonly referred to in game journalism and game-related discussions. For instance, a person may be perfectly cognizant of her preferences to explode and destroy in gameplay but unaware of what kind of physical, cognitive, or emotional challenges she finds enjoyable (see Denisova et al. 2017).

To better understand game choices of latent player segments, a player typology based on gameplay activity preferences is therefore called for. Vahlo, Kaakinen, Holm and Koponen made a cluster analysis to study whether player types can be constructed based on a player's gameplay type (Assault, Manage, Journey, Coordinate, Care) preference scores. The authors identified seven player types or player personas: The Mercenary, The Companion, The Commander, The Adventurer, The Patterner, The Explorer, and The Daredevil (See Vahlo et al. 2017).

To further investigate whether GAIN can be regarded as contingent with the CGD model, a cluster analysis should be conducted. Based on the results presented by Vahlo and Koponen (2018), identified player types can then be utilized in predicting players' game choices. The second and the third research questions of this study are:

RQ2 Can the GAIN model be used in identifying player types and constructing player personas? If so, are these player personas similar to the seven presented by Vahlo et al. (2017)?

RQ3 Is it possible to predict players' game choices by analyzing how the identified player types differ in their habits of playing specific game genres?

\section{Developing and confirming the gameplay activity inventory GAIN}

We began the validation process of the gameplay activity inventory by collecting more empirical evidence on the dimensionality and construct validity of the original CGD inventory. A single exploratory study on a factor structure is not adequate for making a confirmatory factor analysis (Matsunaga 2010). Thus, we first conducted an additional exploratory factor analysis, and then proceeded to design a theory-driven CFA.

\subsection{Data triangulation}

We included in this study a total of 23 items from the original CGD scale (Vahlo et al. 2017). These items were kept very similar to the original ones, although several of the items were rephrased and shortened to describe a specific gameplay activity more precisely than the original items arguably do. The original CGD scale included two items which described tactics and strategy. These items were excluded from GAIN because they converge to gameplay challenge types rather than to gameplay activities. 
The original CGD item of "Exploring the gameworld and uncovering the game's secrets, mysteries and story" was divided into the items "Exploring the gameworld" and "Investigating the story and its mysteries". The item "Showing affection like flirting, hugging, kissing or making love" was modified into the items of "Flirting, seducing and romantic dating" and "Hugging, kissing and making out". Finally, the item of "Dancing, singing or playing instruments together and staying in rhythm" was split into three items of "Dancing to the music", "Playing musical instruments", and "Moving to a beat and staying in rhythm".

Vahlo et al. (2017) suggested that the scale could be developed further by adding items that describe the gameplay activities of decorating, dressing up, customizing appearances, and sports. Along these guidelines, we developed the new items of "Decorating rooms and houses", "Dressing up, applying makeup and choosing looks", "Customizing a character's appearance", "Performing in athletics, gymnastics or other sports", "Doing acrobatic tricks (e.g., in extreme sports)", and "Managing a team and its players". Although the items "Piloting and steering vehicles" and "Racing at a high speed" did not load on any factor in the study by Vahlo et al. (2017), we decided to include them in GAIN due to the popularity of these gameplay activities in contemporary digital games. These changes resulted in a total of 38 inventory items.

Exploratory phases of inventory-development should include an extensive pool of items, which manage to cover all important aspects of the construct under study (Matsunaga 2010). We continued to analyze what kinds of new items could still be added to GAIN by studying a sample of 166 official game instruction booklets. This procedure was a data triangulation for the original content analysis of 700 game review articles reported in Vahlo et al. (2017).

The process included instruction booklets for games published for Playstation, Playstation 2, Playstation 3, Playstation Portable (PSP), Nintendo GameCube, Nintendo Wii, Nintendo WiiU, GameBoy Advance (GBA), Nintendo DS, Nintendo 3DS, Xbox 360, Xbox One and PC in the 1990s and 2000s. The data covered a wide variety of games from sports games and simulation games to strategy games and graphic adventures. The sample size of 166 game instruction manuals was selected based on saturation of the data. As a result of the content analysis, we were able to identify a total of 50 recurrent activities in contemporary digital games. These results were then considered in a focus group meeting with 15 game design course participants and their lecturer who suggested adding two more items to the inventory.

All of the items listed in the original inventory by Vahlo et al. (2017) were supported by the data triangulation process. In addition, the content analysis of 166 game instructions and the results of the focus group meeting suggested that GAIN could include a total of 14 new gameplay activity items that were not identified by Vahlo et al. (2017).

\subsection{Survey on gameplay activity appreciation and an EFA-based item screening}

A survey with the full list of the 52 GAIN items was conducted to explore players' preferences for the recurrent gameplay activities of digital games. Based on the results of the survey, the initial pool of items was to be evaluated and reduced. 


\subsubsection{Sampling}

To screen the items of GAIN, we first recruited 1053 survey respondents in cooperation with an international market research company to obtain a representative sample of the gaming population from Finland (age 18-65 years). The market research company cleaned the data by analyzing participants' response times and by removing cases that replied to the survey too quickly.

At the beginning of the survey, participants were asked to report on a 5-point Likert scale how interested they were in digital games $(1=$ not at all interested, $5=$ very interested). If a participant replied that he or she was not at all interested in digital games, he or she was thanked for participating and instructed to quit the survey. This was an informed decision because our focus was on studying on how players appreciate a variety of gameplay activities, which requires that a person have at least some interest in playing games.

\subsubsection{Materials and procedure}

The survey participants were instructed to think about their gameplay preferences and specify how pleasant $(1=$ very unpleasant, $5=$ very pleasant, 5 -point Likert scale) each of the 52 gameplay activities were for them as players. The survey also included, e.g., a 25-item 5-point Likert inventory for studying participants' motivations to play digital games, a 9-item 5-point Likert inventory on their preferred challenge types in games, and questions regarding participants' age, gender, income, expenditure on games and weekly play time. The data was collected via a web-based survey tool, and it took about $15-20 \mathrm{~min}$ to take the whole survey with either a computer or a mobile device.

It is generally recommended that researchers screen their data to exclude cases of inappropriate responses, especially in the factor analytical studies of scale development (Meade and Craig 2012). According to this principle, we removed from the initial data set $(N=1053)$ participants who showed content nonresponsivity, i.e., who responded in a specific way regardless of the item content. We removed the participants who did not show any or only very minimal variance (only 3 or less responses deviated from the mode response) in their responses. Since the items were randomized by the internet panel provider, we could not check the prevalence of fixed sequence responses.

As a result, the data was cleaned by excluding a total of 174 respondents. The final sample included in the EFA consisted of 879 participants ( $49.5 \%$ men, mean age of 41.6 years). The careless response rate of $16.5 \%$ is in line with the typical estimations for the prevalence of careless responses (see Meade and Craig 2012).

\subsubsection{Results}

An exploratory factor analysis using principal axis factors and promax rotation was made with the data of 879 respondents to investigate the latent structures of players' preferences in gameplay activities. Promax rotation was selected over varimax rotation because varimax rotation does not allow correlations between identified factors, but forces them to be orthogonal to each other (Matsunaga 2010, p. 100). There is, however, 
a well-founded reason to assume that the latent factors of gameplay activity preferences are related to each other, which is why the varimax method could misrepresent the results.

The number of extracted factors was identified by utilizing a parallel analysis (Henson and Roberts 2006). To do so, we first ran an EFA on the data and and then a parallel analysis (PA), which generated an artificial data set for identifying the correct number of factors. The PA test suggested that five factors were to be extracted, and therefore we proceeded to investigate five-factor solutions. We applied two criteria for retaining items in the inventory. First, the factor loading of $>0.50$ was used as a criterion to define whether an item loaded on a factor. Secondly, we accepted only those items that had a discrepancy value of over 0.3 (see Matsunaga 2010).

In the first solution, the items of "Helping others in need", "Playing musical instruments", "Matching tiles or shapes together", "Jumping on platforms and bouncing off of walls" and "Befriending in-game characters" had loadings of $<0.50$ and these items were dropped. We then repeated the process without these five items. The PA test still suggested a five-factor structure. Since each remaining item showed a loading of $>0.50$ on a factor, we continued to investigate the discrepancy values for the remaining 47 items.

A total of five items showed a discrepancy value of under 0.30 . These items were "Attacking, defending and casting spells", "Racing at a high speed", "Defending one's territory, city or base", "Riding animals or other creatures", and "Customizing a character's appearance". After removing these items, we ran an EFA again with the five-factor structure, supported by an additional PA test. In the next solution, four additional items showed a discrepancy value of $<0.30$, and we therefore excluded the items of "Commanding units or troops", "Managing a team and its players", "Piloting and steering vehicles", and "Dancing to the music". We proceeded to run an EFA again. Another item, "Producing vehicles, units or weaponry", showed a relatively high secondary loading, and so it was dropped.

After running an EFA again with five factors as suggested by the PA test, all of the remaining 37 items showed $>0.50$ loading on their primary factor (lowest 0.545 ) and a discrepancy value of over $>0.30$ between the primary and the secondary factor loading (lowest 0.345). The final results and descriptive statistics are shown in Table 1.

Items 1-11 all describe gameplay activities of direct action and aggressive or violent conduct. In the type of gameplay covered by items $12-17$, the player directs, commands and generates resources. In the gameplay activities of 18-24, the player is engaged with the inner development of her character and her endeavors in the gameworld and its stories. Items 25-30 encompass activities in which the player must show skill by acting precisely and accurately in relation to the dynamically changing game environment. Finally, items 31-37 represent gameplay activities that are about nurturing and showing affection and tenderness. All of the five factors revealed in the EFA with 879 respondents were consistent with the original factors identified by Vahlo et al. (2017), and therefore, we call the latent factors Aggression, Management, Exploration, Coordination, and Caretaking.

A total of 23 gameplay activities of the 37-item GAIN (Table 1) were highly similar to the original Core Game Dynamics scale introduced by Vahlo et al. (2017). The items describing racing at a high speed and piloting vehicles loaded in this study on 


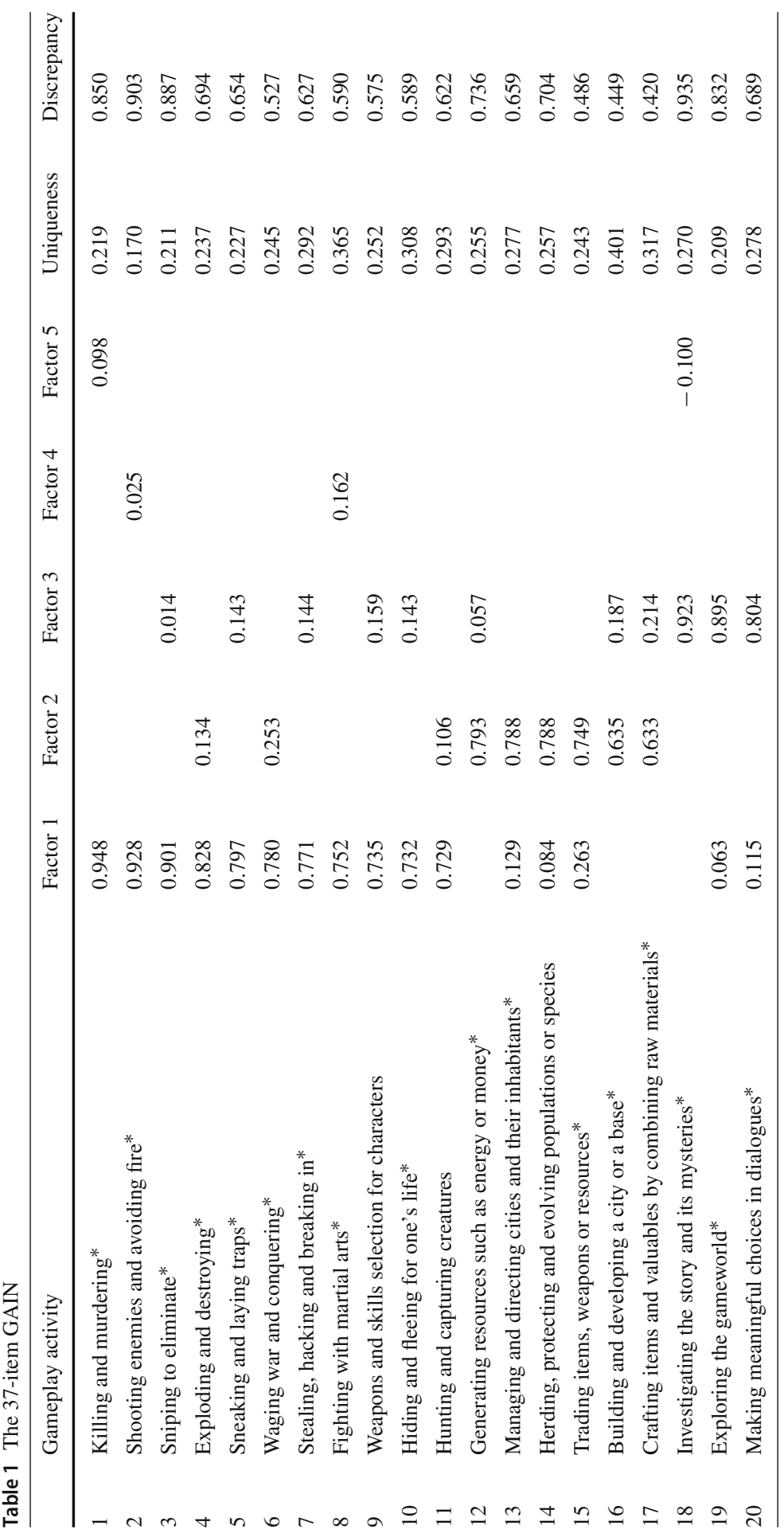




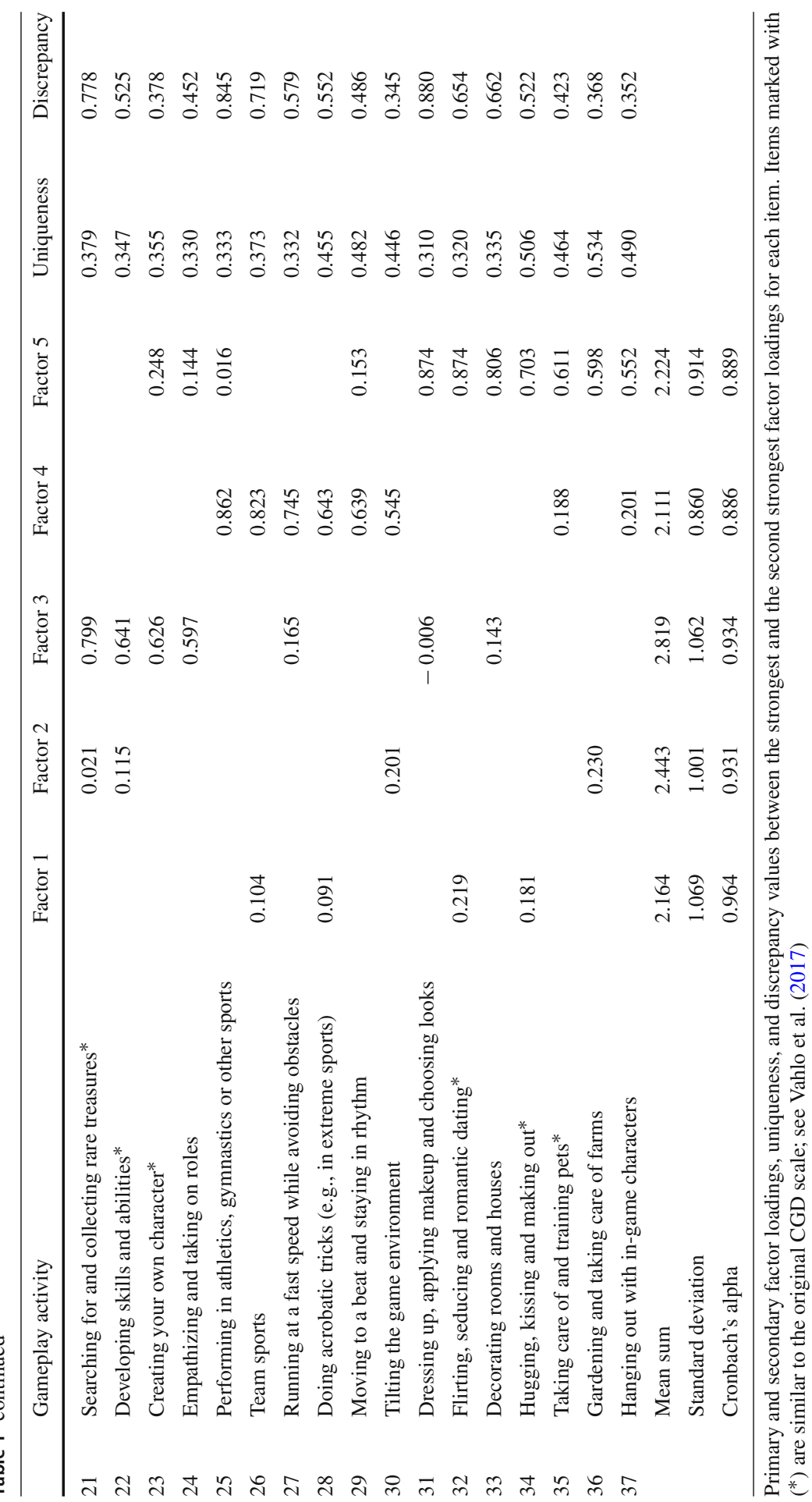


Coordination whereas in the study by Vahlo et al. (2017), these items did not show $>0.50$ loadings on any of the five factors. However, both of these gameplay activity items showed discrepancy values of $<0.30$ and were excluded from the shortlisted 37item version of GAIN. All four of the items that were excluded from the Management factor because they showed a discrepancy of $<0.30$ can be interpreted in a broad framework of 'warfare', which has evident connections with both Aggression and Management. This can be exemplified further by considering the item "Waging war and conquering", which showed a strong primary loading on Aggression (0.78) but also a notable secondary loading on Management (0.25).

As a result of the EFA-based item screening process, in Aggression, a total of 11 items were retained while Exploration and Caretaking both consisted of 7 items and Coordination and Management of 6 items.

\subsection{A confirmatory factor analysis of a 15-item GAIN}

A theory-driven CFA was designed for investigating whether the five-factor structure of GAIN could be confirmed by analyzing cross-cultural survey data (RQ1). We also asked whether the EFA-screened 37-GAIN items could be validated as indicators of the latent factor they were developed and designed to measure. Based on the theoretical considerations, findings presented by Vahlo et al. (2017) and the EFA reported in this article, we formed the following hypotheses:

H1 Players' gameplay activity preferences form five distinctive, but related, dimensions of Aggression, Management, Exploration, Caretaking, and Coordination.

H2 The shortlisted GAIN items are valid indicators for measuring the hypothesized five factors of gameplay activity appreciation.

\subsubsection{Sampling}

A total of 3000 survey respondents (ages 18-65) were obtained from Japan $(N=$ $1500)$ and Canada $(N=1500)$ to construct representative samples from the gaming population of both of these countries. The surveys were conducted simultaneously in January and February 2017 in cooperation with a market-research company by using a web-based tool similar to the one used for recruiting the Finnish sample $(N=1053)$.

\subsubsection{Materials and procedure}

The questions in both surveys were kept identical to the survey conducted in Finland. Thus, the surveys conducted in Canada and Japan included all of the 37 items of the Gameplay Activity Inventory, which were accepted into the final five-factor model presented in Table 1. The surveys were translated into Japanese, English, and French and translated back to Finnish to check the quality of these translations. Respondents from Canada had an opportunity to choose whether they would reply to the English or the French version of the survey.

The samples from Japan and Canada were cleaned with a similar procedure as was used with the Finnish sample. As a result, a total of 322 participants were removed 
from the Japanese sample, which resulted in 1178 respondents $(55.0 \%$ men, mean age 41.8 years). From the sample collected in Canada, we removed 178 participants. The Canadian sample included in this study had 1322 respondents $(50.4 \%$ men, mean age 40.8 years). The combined data from Japan and Canada had 2500 participants (52.6 $\%$ men, mean age 41.3 years).

\subsection{Results}

To conduct a CFA on the five-factor model of gameplay activity preference types, we constructed 3-item scales for each of the five hypothesized factors. The rationale for designing 3-item scales was to develop a psychometrically sound instrument for measuring players' gameplay activity preferences. A 15-item measurement for gameplay activity appreciation would be more easily included in future game research surveys than the full 37-item inventory. Three items per latent construct is generally regarded as a sufficient minimum for constructing CFA models (Brown 2015, pp. 61-62).

The 15 items were selected based on the following criteria: (1) the discrepancy value of the item was high ( $>0.30)$, and (2) the item showed a strong loading on the corresponding factor $(>0.50)$ in the EFA reported earlier in this article $(N=879)$. Furthermore, (3) the qualitative aspects the item did not overlap with the other two selected items but rather managed to portray an additional facet of the hypothesized gameplay preference dimension, and (4) each item could be argued to characterize a considerable proportion of contemporary digital games.

The analyses were conducted with structural equation modelling (SEM) and by using the statistical software, Stata 14.2, and the maximum likelihood estimation procedure. We conducted a CFA on the five-factor model of gameplay activity preference factors with the combined data from Canada $(N=1322)$ and Japan $(N=1178)$, which resulted in a data sample of 2500 respondents. The measurement model for reporting the CFA is presented in Fig. 2, and the descriptive statistics for the shortlisted 15 GAIN items are reported in Table 2.

The construct validity of the five-factor construct was investigated by calculating the comparative fit index (CFI), the Tucker Lewis Index (TLI), the root mean squared error of approximation (RMSEA), and the standardized root mean squared residual score (SRMR). The chi square test $\left(\chi^{2}\right)$ was not utilized since this test has been argued as ill-fitting for large sample sizes, especially when the correlations in the model are strong (Russell 2002; Matsunaga 2010, p. 106). RMSEA and SRMR values are generally regarded as a good fit for the data if the values are at or under 0.05 and acceptable with values under 0.08. A CFI score of $>0.90$ is considered acceptable and > 0.95 good. (Brown 2015; Acock 2013, pp. 24-31; Schreiber et al. 2006, p. 330; Kline 2010; Marsh et al. 2004; Hu and Bentler 1999)

The model we present in Fig. 2 had the following fit to the data: RMSEA 0.050, CFI 0.978, TLI 0.970, and SRMR 0.028. These results suggest construct validity of the model and a close fit to the data of 2500 respondents from Japan and Canada (see Schreiber et al. 2006). We also estimated the goodness-of-fit for the 15-item GAIN separately for the two datasets obtained from Canada and Japan. The model showed a good fit with the data collected from both Canada $(N=1322)$ and Japan $(N=1178)$. 


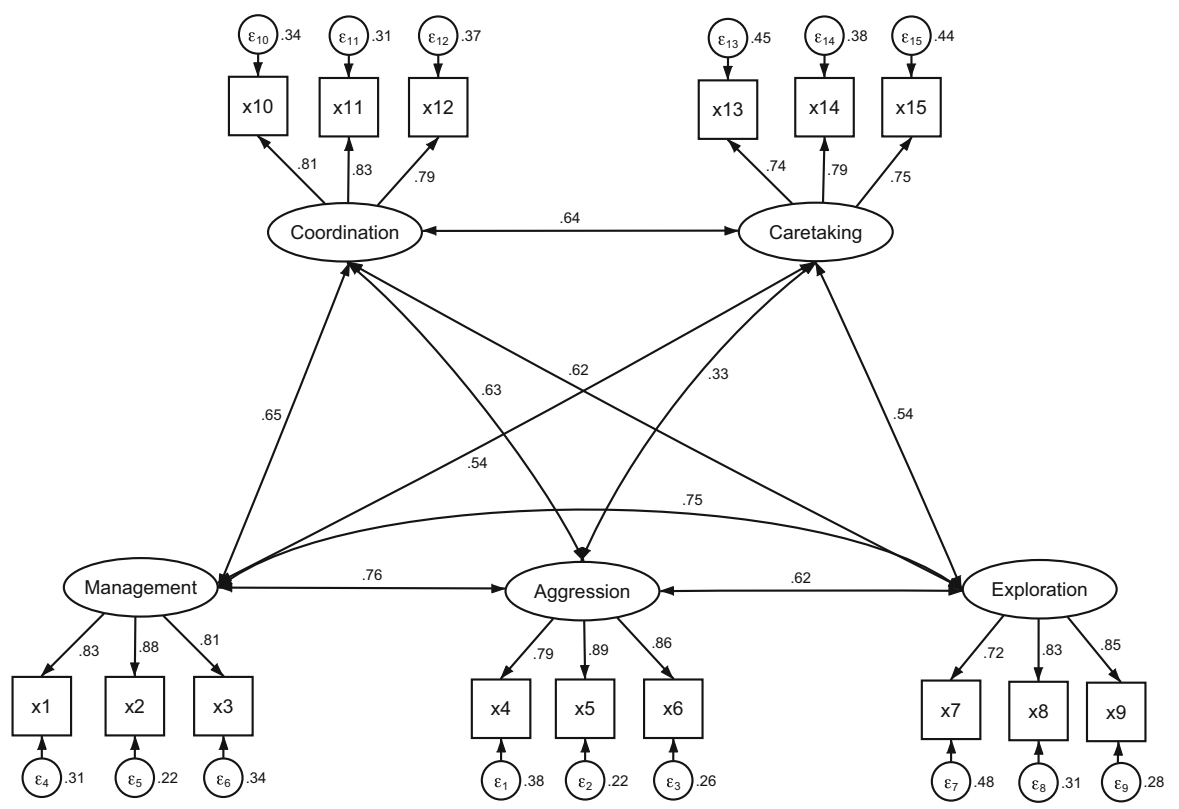

Fig. 2 The measurement model reporting confirmatory factor analysis for the five factors of gameplay activity preferences $(N=2500)$. All loadings for the 15 -item version of the scale are significant on the level $p<0.001$. See Table 7 in "Appendix" for information about Standardized and standardized factor loadings for the CFA model

The goodness of fit values for the data from Canada were RMSEA 0.052, CFI 0.975, TLI 0.967, and SRMR 0.032, and for the data from Japan: RMSEA 0.053, CFI 0.976, TLI 0.969, and SRMR 0.033.

\subsection{Convergent and discriminant validity}

To validate a construct, convergent validity and discriminant validity of the model should be investigated. To show convergence, the factor loadings for all items should be strong, preferably $>0.7$. The five-factor model we present in Fig. 2 fulfills this criterion of unidimensionality, since the lowest factor loading was 0.72 for the item of "Developing skills and abilities" $(\times 7)$.

Depending on the theoretical framework, the correlations between latent constructs in a model can be desired or undesired (Harrington 2009, pp. 6-7; Kline 2010, pp. 7172). We expected that the correlations between the latent constructs of a CFA model would be at least moderate because players who enjoy gameplay often play a significant variety of games. Moreover, we argue that Aggression, Management, Exploration, Coordination, and Caretaking are all facets of the phenomenon of gameplay activity appreciation, and we expected therefore to find significant correlations between each of the five constructs.

With the exception of the correlation between Aggression and Caretaking, all of the five factors of gameplay activity preferences correlated moderately $(>0.40)$ or 
Table 2 Descriptive statistics for the 15-item GAIN $(N=2500)$

\begin{tabular}{|c|c|c|c|c|c|}
\hline & Variable & Mean & $\mathrm{SD}$ & Skewness & Kurtosis \\
\hline $\mathrm{x} 1$ & $\begin{array}{l}\text { Managing and directing cities } \\
\text { and their inhabitants }\end{array}$ & 2.836 & 1.204 & 0.034 & 2.161 \\
\hline $\mathrm{x} 2$ & $\begin{array}{l}\text { Trading items, weapons or } \\
\text { resources }\end{array}$ & 2.836 & 1.215 & 0.031 & 2.122 \\
\hline $\mathrm{x} 3$ & $\begin{array}{l}\text { Generating resources such as } \\
\text { energy or money }\end{array}$ & 3.049 & 1.197 & -0.153 & 2.228 \\
\hline $\mathrm{x} 4$ & Killing and murdering & 2.364 & 1.267 & 0.492 & 2.141 \\
\hline$\times 5$ & Sneaking and laying traps & 2.656 & 1.256 & 0.144 & 1.970 \\
\hline x6 & Sniping to eliminate enemies & 2.738 & 1.310 & 0.133 & 1.933 \\
\hline $\mathrm{x} 7$ & Developing skills and abilities & 3.432 & 1.117 & -0.432 & 2.611 \\
\hline $\mathrm{x} 8$ & Exploring the gameworld & 3.263 & 1.225 & -0.263 & 2.189 \\
\hline $\mathrm{x} 9$ & $\begin{array}{l}\text { Making meaningful choices in } \\
\text { dialogues }\end{array}$ & 3.126 & 1.194 & -0.168 & 2.246 \\
\hline $\mathrm{x} 10$ & Tilting the game environment & 2.650 & 1.142 & 0.119 & 2.248 \\
\hline $\mathrm{x} 11$ & $\begin{array}{l}\text { Running at a fast speed while } \\
\text { avoiding obstacles }\end{array}$ & 2.769 & 1.199 & 0.034 & 2.100 \\
\hline $\mathrm{x} 12$ & $\begin{array}{l}\text { Performing in athletics, } \\
\text { gymnastics or other sports }\end{array}$ & 2.585 & 1.201 & 0.213 & 2.102 \\
\hline $\mathrm{x} 13$ & $\begin{array}{l}\text { Dressing up, applying make up } \\
\text { and choosing looks }\end{array}$ & 2.621 & 1.278 & 0.245 & 1.996 \\
\hline $\mathrm{x} 14$ & $\begin{array}{l}\text { Gardening and taking care of } \\
\text { farms }\end{array}$ & 2.792 & 1.263 & 0.041 & 1.985 \\
\hline $\mathrm{x} 15$ & Taking care of and training pets & 2.807 & 1.256 & 0.064 & 2.019 \\
\hline
\end{tabular}

strongly ( $>0.60$ ) with each other. The strongest correlation was between the latent constructs of Management and Aggression (0.76), and Management and Exploration (0.75). All the correlations between the five latent factors were statistically significant $(p<0.001)$.

We continued to test the convergent validity of the model by calculating composite reliability (CR) estimates for each of the five constructs included in the CFA (Fig. 2). It is generally held that an acceptable value for CR is 0.7 (see Zait and Bertea 2011). The CR estimates for the 3-item five factors were: Aggression (0.883), Management (0.879), Exploration (0.841), Coordination (0.852), and Caretaking (0.802).

To establish both the convergent and discriminant validity for the gameplay activity construct (Fig. 2), we conducted an average variance extracted analysis (AVE), which has been recommended for confirmatory stages of research (Farrell 2009; Zait and Bertea 2011). AVE is used to investigate the average amount of variance in the observed variables that is explained by the latent construct. The value of AVE should be $>0.50$ or higher for each construct to demonstrate convergent validity (Fornell and Larcker 1981; Farrell 2009).

AVE is then utilized to test whether the square root of the average variance of each construct is larger than the shared variance, i.e., square of the correlation, between 
Table 3 The average variance extracted analysis on the five-factor model of gameplay activity type preferences (AVE values bolded) and shared variances between the constructs

\begin{tabular}{llllll}
\hline & Aggression & Management & Exploration & Coordination & Caretaking \\
\hline Aggression & $\mathbf{0 . 7 1 6}$ & & & & \\
Management & 0.576 & $\mathbf{0 . 7 0 8}$ & & & \\
Exploration & 0.387 & 0.565 & $\mathbf{0 . 6 4 0}$ & & \\
Coordination & 0.398 & 0.419 & 0.384 & $\mathbf{0 . 6 5 8}$ & \\
Caretaking & 0.111 & 0.297 & 0.294 & 0.404 & $\mathbf{0 . 5 7 6}$ \\
\hline
\end{tabular}

The AVE test was calculated according to the formula presented by Fornell and Larcker (1981, p. 46), which takes the measurement error of the variables into account

two constructs within the model. If the AVE for each construct exceeds its shared variance with all of the other constructs, the test supports discriminant validity for the model (Farrell 2009; Fornell and Larcker 1981, pp. 45-46). The AVE for each of the five gameplay activity preference factors was $>0.50$ and greater than the shared variance between it and other factors. This result together with factor loadings and composite reliability (CR) estimates supports convergent and discriminant validity of the five-factor model of the 15-item GAIN (Fig. 2, Table 3).

\section{Player clusters and game choice}

We continued to perform a cluster analysis for the combined data from Finland, Canada, and Japan $(\mathrm{N}=3379)$ to investigate whether player types could be identified based on players' gameplay activity type preferences (RQ2). We computed $\mathrm{z}$-standardized factor scores for each participant by using the confirmed 15-item GAIN. Next, the standardized scores were utilized in a complete linkage cluster analysis. The Calinski-Harabasz pseudo-F stopping rule identified six player clusters in the data. Descriptive statistics of the background variables for each player type are presented in Table 4.

We can observe from Table 4 that the six player types have distinctive characteristics in regard to cluster size, weekly play time, gender proportion, motivations, challenge type and gameplay activity preferences. Player Type 1 (447 participants, 57.5\% men) showed a high preference for Management, and low for Coordination. In contrast to this, Player Type 2 (279 participants, $60.2 \%$ men) strongly showed enjoyment of Coordination but showed a slight dislike for Management and Caretaking. Both of these player types were over-represented in Japan.

Player Type 3 (647 participants, 24.9\% men) favored Caretaking but did not enjoy Aggression. Similarly, Player Type 4 (588 participants, $40.3 \%$ men) despised Aggression, but this player type showed a moderate preference for Exploration, and also some for Coordination. Player Type 3 was under-represented in Canada. In contrast to this, Player Type 4 was over-represented in Canada and also under-represented in Finland.

Player Type 5 (592 participants, 46.5\% men) enjoyed Exploration very much but showed a mild dislike for all other dimensions of gameplay activities. This player 
Table 4 Descriptive statistics for the six player types $(N=3337)$

\begin{tabular}{|c|c|c|c|c|c|c|}
\hline & Type 1 & Type 2 & Type 3 & Type 4 & Type 5 & Type 6 \\
\hline$N$ & 447 & 279 & 647 & 588 & 592 & 784 \\
\hline$\%$ of the whole sample & $13.4 \%$ & $8.4 \%$ & $19.4 \%$ & $17.7 \%$ & $17.7 \%$ & $23.5 \%$ \\
\hline$\%$ Canada $(\mathrm{n}=1307)$ & $12.6 \%$ & $8.9 \%$ & $16.8 \%$ & $20.3 \%$ & $15.8 \%$ & $25.6 \%$ \\
\hline$\%$ Finland $(n=871)$ & $12.6 \%$ & $6.4 \%$ & $21.2 \%$ & $13.7 \%$ & $20.8 \%$ & $25.3 \%$ \\
\hline$\%$ Japan $(\mathrm{n}=1159)$ & $14.8 \%$ & $9.2 \%$ & $20.9 \%$ & $17.6 \%$ & $17.6 \%$ & $19.8 \%$ \\
\hline Men & $58 \%$ & $60 \%$ & $25 \%$ & $40 \%$ & $47 \%$ & $81 \%$ \\
\hline Mean age & 42.3 & 39.0 & 42.5 & 43.9 & 40.7 & 38.9 \\
\hline Weekly play hours & 20.6 & 19.5 & 18.9 & 18.0 & 19.6 & 22.2 \\
\hline Gameplay mean & 2.75 & 2.75 & 2.45 & 2.84 & 2.46 & 3.61 \\
\hline Challenge mean & 3.08 & 3.20 & 3.01 & 3.37 & 3.04 & 3.31 \\
\hline Motivation mean & 3.00 & 3.04 & 2.73 & 3.07 & 2.96 & 3.31 \\
\hline Interest in games mean & 3.29 & 3.27 & 3.04 & 3.10 & 3.48 & 3.72 \\
\hline \multicolumn{7}{|l|}{ Factor scores } \\
\hline Aggression & -0.40 & 0.15 & -0.88 & -1.54 & -0.40 & 0.89 \\
\hline Management & 1.23 & -0.63 & -0.38 & 0.11 & -0.32 & 0.26 \\
\hline Coordination & -1.03 & 1.26 & -0.35 & 0.56 & -0.66 & -0.36 \\
\hline Caretaking & 0.10 & -0.53 & 1.47 & 0.02 & -0.27 & -1.37 \\
\hline Exploration & 0.11 & -0.24 & 0.15 & 0.85 & 1.66 & 0.57 \\
\hline \multicolumn{7}{|l|}{ Factor sum comparisons } \\
\hline Aggression & $0 \%$ & $15 \%$ & $-25 \%$ & $-25 \%$ & $-15 \%$ & $47 \%$ \\
\hline Management & $26 \%$ & $-11 \%$ & $-19 \%$ & $6 \%$ & $-17 \%$ & $16 \%$ \\
\hline Coordination & $-18 \%$ & $29 \%$ & $-14 \%$ & $23 \%$ & $-23 \%$ & $3 \%$ \\
\hline Caretaking & $6 \%$ & $-6 \%$ & $28 \%$ & $10 \%$ & $-14 \%$ & $-25 \%$ \\
\hline Exploration & $-6 \%$ & $-14 \%$ & $-15 \%$ & $9 \%$ & $15 \%$ & $11 \%$ \\
\hline
\end{tabular}

Gameplay preference differences between the player types are calculated as $d_{k}^{x}=\frac{\bar{x}_{k}-\bar{x}}{\bar{x}} \cdot 100 \%$, where $\bar{x}_{k}$ is the mean of analyzed variable $x$ (e.g., Aggression, Management) in player clusters $k$ (e.g., Type 1, Type 2) and $\bar{x}$ the sample mean of analyzed. Challenge preference, motivations to play, and interest in games are reported as mean sums on 5-point Likert scales. Weekly play is reported as mean play hours

type was over-represented in Finland. Finally, Player Type 6 (784 participants, 80.8\% men), which was under-represented in Japan, favored Aggression and moderately Exploration, but showed dislike for Caretaking. A total of 42 participants were not included in any of the six clusters, because they had replied similarly to all of the 15 items of GAIN.

\subsection{Comparing GAIN and CGD player types}

We then continued to study RQ2 by comparing the six GAIN player types with the seven CGD player types presented by Vahlo et al. (2017). The purpose of this analysis was to explore whether the player types in these two studies were congruent. We were 
Table 5 GAIN player types as allocated into the CGD player types Vahlo et al. (2017), based on the highest correlation between the z-standardized GAIN factor vectors per each participant and the mean factor scores of the seven CGD player types

\begin{tabular}{|c|c|c|c|c|c|c|c|}
\hline & Type 1 & Type 2 & Type 3 & Type 4 & Type 5 & Type 6 & Total \\
\hline The Mercenary & $\begin{array}{l}28 \\
(-0.06)\end{array}$ & $\begin{array}{l}11 \\
(0.24)\end{array}$ & $\begin{array}{l}12 \\
(-0.94)\end{array}$ & $\begin{array}{l}10 \\
(-0.38)\end{array}$ & $\begin{array}{l}13 \\
(0.13)\end{array}$ & $\begin{array}{l}354 \\
(0.97)\end{array}$ & 428 \\
\hline The Adventurer & $\begin{array}{l}24 \\
(-0.27)\end{array}$ & $\begin{array}{l}49 \\
(0.12)\end{array}$ & $\begin{array}{l}64 \\
(-0.27)\end{array}$ & $\begin{array}{l}16 \\
(0.07)\end{array}$ & $\begin{array}{l}289 \\
(0.79)\end{array}$ & $\begin{array}{l}123 \\
(0.64)\end{array}$ & 565 \\
\hline The Commander & $\begin{array}{l}161 \\
(0.54)\end{array}$ & $\begin{array}{l}18 \\
(-0.12)\end{array}$ & $\begin{array}{l}15 \\
(-0.64)\end{array}$ & $\begin{array}{l}33 \\
(0.17)\end{array}$ & $\begin{array}{l}26 \\
(0.14)\end{array}$ & $\begin{array}{l}149 \\
(0.64)\end{array}$ & 402 \\
\hline The Daredevil & $\begin{array}{l}49 \\
(-0.32)\end{array}$ & $\begin{array}{l}49 \\
(0.55)\end{array}$ & $\begin{array}{l}28 \\
(-0.76)\end{array}$ & $\begin{array}{l}0 \\
(-0.58)\end{array}$ & $\begin{array}{l}2 \\
(-0.75)\end{array}$ & $\begin{array}{l}55 \\
(0.33)\end{array}$ & 183 \\
\hline The Companion & $\begin{array}{l}131 \\
(0.48)\end{array}$ & $\begin{array}{l}35 \\
(-0.42)\end{array}$ & $\begin{array}{l}447 \\
(0.72)\end{array}$ & $\begin{array}{l}289 \\
(0.81)\end{array}$ & $\begin{array}{l}128 \\
(0.30)\end{array}$ & $\begin{array}{l}29 \\
(-0.60)\end{array}$ & 1059 \\
\hline The Patterner & $\begin{array}{l}19 \\
(-0.53)\end{array}$ & $\begin{array}{l}95 \\
(0.87)\end{array}$ & $\begin{array}{l}41 \\
(-0.47)\end{array}$ & $\begin{array}{l}29 \\
(0.34)\end{array}$ & $\begin{array}{l}19 \\
(-0.32)\end{array}$ & $\begin{array}{l}44 \\
(0.05)\end{array}$ & 247 \\
\hline The Explorer & $\begin{array}{l}35 \\
(0.05)\end{array}$ & $\begin{array}{l}22 \\
(0.26)\end{array}$ & $\begin{array}{l}40 \\
(-0.14)\end{array}$ & $\begin{array}{l}211 \\
(0.86)\end{array}$ & $\begin{array}{l}115 \\
(0.45)\end{array}$ & $\begin{array}{l}30 \\
(0.14)\end{array}$ & 453 \\
\hline Total & 447 & 279 & 647 & 588 & 592 & 784 & 3337 \\
\hline
\end{tabular}

The Pearson's correlations are are reported in parentheses

also interested in identifying whether the CGD player types could be argued to be persistent.

To compare the player types of these two studies, we classified respondents of our current sample into the seven CGD player types presented by Vahlo et al. (2017). This was done by calculating the Pearson's correlations between the vectors of our study participants' z-standardized factor scores and the mean factor scores of the seven player types that Vahlo et al. (2017) reported in their study. Participants of our study were associated with the CGD player types according to the highest revealed correlation (Table 5).

Based on the results we report in Table 5, it can be concluded that GAIN player types share clear similarities with CGD player types. Player Type 6 showed a very high correlation with the mean profile of The Mercenary type. Player Type 2 was very strongly correlation with The Patterner type, and Player Type 4 had a very high correlation with both of The Explorer and The Companion type. Player Type 5 was strongly correlated with The Adventurer type, and Player Type 3 with The Companion type. Finally, Player Type 1 had a moderate correlation with The Commander type and also with The Companion type.

Based on these findings, we decided to label the GAIN player types according to the CGD player personas: Mercenary (Player Type 6), Adventurer (Player Type 5), Explorer (Player Type 4), and Companion (Player Type 3). Since Player Type 1 was correlated not only with The Commander type, but also with The Companion type who dislikes Aggression, we decided to label this player type Supervisor, because the latter term is not associated with military activities. Similarly, Player Type 2 was 
correlated not only with The Patterner type, but also with The Daredevil type. Since The Daredevil enjoys both Coordination and direct action, including, e.g., racing and sports (see Vahlo et al. 2017), we decided to call this player persona Acrobat.

\subsection{Game choices of the six GAIN player types}

The surveys conducted in Finland, Japan, and Canada included questions that enquired about respondents' habits of playing games by asking how often they had played games of different genres during the previous 12 months (17-item scale of which we report here 11 items on the 5 -point Likert scale, $1=$ not at all, $5=$ very often). To investigate how GAIN can be utilized in predicting game choice (RQ3), we designed a model where the outcome variable was the player type and binary transformations of RQ3 were used as predictor variables. In transformation, a variable gets a value of 0 if the respondent never plays that genre (original value $=1$ ) and 1 if she/he plays it at least sometimes (original value $>1$ ). Gender and age were included in the model as control variables. Predictive margins of each genre and player type are presented in Table 6.

A habit of playing simulation games and strategy games predicted that a person belonged to the Supervisor cluster. Also, playing sports games, racing games, and puzzles negatively predicted the identity of the Supervisor. In contrast to this, playing sports games and party games strongly predicted the Acrobat type, alongside a lower age.

A habit of playing party games also strongly predicted the Companion type, but the single strongest predictor for this player type was being female. Also, playing simulation games predicted belonging to this player type, but playing action games, action-adventure games, role-playing games, and strategy games all predicted negatively that one was of this player type.

The predictors for Explorers were higher age, being female, and playing sports games, party games and platformer games. Playing strategy games and role-playing games negatively predicted this player type. Being of the Adventurer type was predicted by the habit of playing role-playing games and action-adventure games. However, playing action games, racing games, simulations, and sports games were all negative predictors for the Adventurers. Finally, playing action games, racing games, strategy games, and being a younger man all predicted the Mercenary type, while playing puzzle games, simulation games, and party games were negative predictors for this player type.

\section{Discussions and conclusions}

The purpose of this study was to develop and validate a psychometrically sound short instrument for modeling player profiles based on gameplay preferences, and demonstrate the usefulness of this approach in predicting players' game choices. This was done by forming an approach to the structuration theoretical and TSQA views on media choice (Webster 2011, 2014; Wolling 2009) and by empirically investigating how players appreciate recurrent gameplay activities in contemporary digital games. 
Table 6 Multinomial logit based estimates how a habit of playing game genres, gender, and age predict GAIN player types

\begin{tabular}{|c|c|c|c|c|c|c|}
\hline & Supervisor & Acrobat & Companion & Explorer & Adventurer & Mercenary \\
\hline Action & -0.0218 & 0.00938 & $-0.0635^{* *}$ & -0.0480 & $-0.0703^{* *}$ & $0.194^{* * * *}$ \\
\hline$(40.6 \%)$ & $(-1.00)$ & $(0.57)$ & $(-2.85)$ & $(-2.15)$ & $(-2.91)$ & $(8.22)$ \\
\hline Action-adventure & 0.00672 & -0.0251 & $-0.0786^{* * *}$ & -0.0361 & $0.0785^{* *}$ & $0.0545^{*}$ \\
\hline$(42.5 \%)$ & $(0.27)$ & $(-1.32)$ & $(-3.30)$ & $(-1.55)$ & $(3.16)$ & $(2.06)$ \\
\hline Adventure & -0.00341 & 0.0118 & 0.00315 & -0.0225 & 0.0145 & -0.00360 \\
\hline$(36.7 \%)$ & $(-0.14)$ & $(0.74)$ & $(0.14)$ & $(-0.97)$ & $(0.59)$ & $(-0.15)$ \\
\hline Racing & -0.0360 & 0.0299 & -0.0302 & 0.0341 & $-0.0499 *$ & $0.0522 *$ \\
\hline$(42.8 \%)$ & $(-1.96)$ & $(1.81)$ & $(-1.63)$ & $(1.72)$ & $(-2.28)$ & $(2.45)$ \\
\hline Puzzle & $-0.0387^{*}$ & -0.0192 & $0.0396 *$ & 0.0343 & 0.0301 & $-0.0462 *$ \\
\hline$(72.0 \%)$ & $(-2.54)$ & $(-1.49)$ & $(2.40)$ & $(1.96)$ & $(1.64)$ & $(-2.52)$ \\
\hline Rpg & -0.0160 & $-0.0315^{*}$ & $-0.0411^{*}$ & $-0.0493^{*}$ & $0.117 * * *$ & 0.0213 \\
\hline$(44.4 \%)$ & $(-0.78)$ & $(-2.02)$ & $(-2.15)$ & $(-2.48)$ & $(5.76)$ & $(1.03)$ \\
\hline Simulation & $0.0598 * *$ & -0.0194 & $0.0583 * *$ & 0.0123 & $-0.0530^{*}$ & $-0.0580 *$ \\
\hline$(40.5 \%)$ & $(3.14)$ & $(-1.28)$ & $(2.98)$ & $(0.63)$ & $(-2.33)$ & $(-2.51)$ \\
\hline Sports & $-0.0694 * * *$ & $0.0547 * * *$ & 0.0239 & $0.0730 * * *$ & $-0.0780 * * *$ & -0.00428 \\
\hline$(36.7 \%)$ & $(-3.73)$ & $(4.17)$ & $(1.27)$ & $(3.67)$ & $(-3.43)$ & $(-0.21)$ \\
\hline Strategy & $0.0821 * * *$ & 0.00556 & $-0.0465^{*}$ & $-0.0743 * * *$ & -0.0172 & $0.0504 *$ \\
\hline$(38.8 \%)$ & $(4.16)$ & $(0.38)$ & $(-2.33)$ & $(-3.67)$ & $(-0.77)$ & $(2.30)$ \\
\hline Platform & -0.00768 & -0.00728 & -0.0117 & $0.0453 *$ & 0.00711 & -0.0258 \\
\hline$(43.6 \%)$ & $(-0.39)$ & $(-0.45)$ & $(-0.62)$ & $(2.32)$ & $(0.34)$ & $(-1.18)$ \\
\hline Party & -0.0159 & $0.0422 * *$ & $0.0957 * * *$ & $0.0667 * * *$ & -0.0425 & $-0.146^{* * *}$ \\
\hline$(31.0 \%)$ & $(-0.86)$ & $(3.16)$ & $(5.19)$ & $(3.45)$ & $(-1.94)$ & $(-6.74)$ \\
\hline \multirow[t]{2}{*}{ Gender } & $-0.0298 *$ & -0.0207 & $0.169 * * *$ & $0.0771 * * *$ & 0.0102 & $-0.205^{* * *}$ \\
\hline & $(-2.02)$ & $(-1.80)$ & $(11.81)$ & $(5.02)$ & $(0.65)$ & $(-11.73)$ \\
\hline \multirow[t]{2}{*}{ Age } & 0.000363 & $-0.000997 *$ & 0.000769 & $0.00290 * * *$ & -0.00106 & $-0.00197^{* *}$ \\
\hline & $(0.66)$ & $(-2.21)$ & $(1.40)$ & $(4.95)$ & $(-1.75)$ & $(-3.06)$ \\
\hline
\end{tabular}

Positive values in gender are associated with the female gender. The percentage of the respondents $(N=$ 3337) who reported to play specific game genres at least occasionally are reported under each genre label in parenthesis

$* p<0.05, * * p<0.01, * * * p<0.001$

We investigated whether the five-factor structure of gameplay preference dimensions presented by Vahlo et al. (2017) could be validated by developing the gameplay activity inventory (GAIN) and by conducting a CFA with 15-item version of the inventory (RQ1). The CFA consisted of five 3-item measurements for the hypothesized latent constructs of Aggression, Management, Exploration, Coordination, and Caretaking. The CFA showed a close fit to the combined data from Japan and Canada, and also to both of these data sets when investigated separately. By conducting a CFA, we were able to confirm the five distinctive, but related, dimensions of gameplay activity preference types (H1), and we demonstrated that the GAIN items are valid indicators for measuring the five factors of gameplay activity appreciation $(\mathrm{H} 2)$. 
We then conducted a cluster analysis $(\mathrm{N}=3379)$ and observed that the 15-GAIN could be used in constructing player types (RQ2). By comparing the factor score vectors of the respondents of our sample with the mean factor score vector of the CGD study by Vahlo et al. (2017), we were able to conclude that the six GAIN player types were mostly similar with the seven CGD player types. Four of the GAIN player types had a very similar profile to some of the CGD player personas. Therefore, we labeled these types according to the CGD model: Mercenary, Adventurer, Companion, and Explorer. Two of the GAIN player types had notable differences in their qualitative characteristics in comparison to the CGD types. We labeled these two personas as Acrobat and Supervisor.

The six player types differed clearly in their size, gender proportion and gameplay activity type preference profiles (Table 4). Also, it should be noted that the Mercenary type was clearly more typical for men than for women, and that the great majority of Companions were women. However, the Adventurer type and the Supervisor type were almost equally represented by both men and women, and the gender gap between the Acrobat and the Explorer types was only moderate. Mercenaries reported to be more interested in games and motivated to play than the other five player types. This player type was also the only one that had a higher mean preference score for gameplay activities than for gameplay challenges (Table 4). Indeed, Explorers who spent the least time playing digital games, reported a stronger preference in gameplay challenges than Mercenaries. Interestingly, the Mercenary type had the lowest mean age and the Explorer had the highest mean age, which indicates a correlation between higher age and preference in gameplay challenge types.

Adventurers reported a high interest in games, but only from the perspective of the Exploration type of gameplay. This result is in line with what Vahlo (2018) has recently argued: players who are fascinated by the story elements in games find games more meaningful than players who do not appreciate the dimension of fiction and fantasy in gameplay. The GAIN player types demonstrate that stereotypical male and female players may exist in the large player clusters of the Mercenary type and the Companion, but also that most of the players do not fall into these two player clusters but instead into player types that have quite similar proportions of both male and female players.

Finally, we conducted a multinomial logit regression analysis to study whether the GAIN player profiles could be utilized in predicting game choice (RQ3). The main result of this analysis was that players' habits of playing games of different genres do predict their player type, and thus it can be argued that the GAIN model can, in principle, be utilized in targeted marketing and in generating game recommendations for identified player profiles. It is worth noting that all genres other than adventure games were significant predictors for the GAIN player types (Table 6).

The GAIN player profiles are linked to genres people play, which validates the potential of GAIN in predicting game choices. Importantly, the six player types are associated with a habit (or the lack thereof) of playing multiple game genres. Therefore it cannot be concluded that Mercenaries equate to action game players or that Adventurers are merely RPG players. Indeed, among Mercenaries prevalence of playing puzzle games is higher than playing action games (Table 6). This result shows the limits of using only data on genre playing habits in player profiling and in generating personalized recommendations. 
These results (Table 6) can be argued to be partly consistent with the findings by Greenberg et al. (2010), who found that male players preferred physical games (action, racing, and sports) over imaginative role-playing games and puzzles, whereas the latter were the most favored game types by females. Furthermore, Terlecki et al. (2011) found that both men and women enjoy adventure games, which can be argued to include many elements of Exploration.

\subsection{Limitations of the current study}

Similar to the game dynamics approach by Vahlo et al. (2017), the gameplay activity inventory (GAIN) is influenced by the data utilized in developing the inventory items, and by researchers' interpretations. Notably, the data of 166 game instruction manuals did not cover mobile game titles, which may suggest that GAIN is currently best adapted for investigating non-mobile gameplay preferences and player profiles. Relatedly, the inventory may be a better fit for investigating players' preferences in non-mobile games because many mobile games only include a few gameplay activities.

GAIN is primarily an approach for identifying player profiles (Vahlo et al. 2017), gameplay preferences, and game choice, although still questionable is how well a respondent's GAIN responses predict which games a player chooses to play as she browses through her options, e.g., in game marketplaces. Investigating this question would require that the GAIN model would also be utilized in analyzing behavioral data instead of mere survey data made up of players' reflections on their own gameplay preferences.

Like other applications of the TSQA, the GAIN instrument is perhaps not wellsuited for those individuals who have no or very little experience in playing digital games. A person may find it difficult to reply to a questionnaire about different types of gameplay if one lacks first-hand experience of playing games.

It must also be noted that, although the five-factor structure was confirmed in this study, the player types remain context-dependent and unstable, due to the nature of available clustering methods. In other words, the five orientations of gameplay preferences can be utilized widely in game research, but player clusters should be constructed by taking the unique characteristic of each sample into the consideration.

\subsection{Directions for future research}

Video game genres are primarily separated from each other based on the kinds of interactivity they afford for the player in gameplay (Apperley 2006; Landay 2014). Research on game preferences and gameplay type preferences thus differs from other player profiling methods, e.g., from studies on motivations to play and player behavior research, by providing tools for understanding players' habitual game choices. Because of this, the gameplay type preference approach can inform the game industry in how to better design, develop and market games with better market fit.

The GAIN model could also be utilized in developing game recommendation models based on review-based player profile building, review-based game profile building, or both (see Chen et al. 2015). For this purpose, the GAIN approach could be imple- 
mented in analyzing users' behavioral data on, e.g., game marketplaces or game streaming services. By combining the GAIN model with meta-data of game titles (e.g., genres and tags) and players' game ratings, the approach could make use of both content-based filtering and collaborative filtering. The GAIN approach may also provide more insight into latent trends in gaming cultures and usages of different game technologies.

In future research, it would be important to investigate how the gameplay type preference approach may open new horizons for understanding expenditure of time and money on digital games. For this purpose, the relationships between gameplay activity preferences, gameplay challenge preferences, and gameplay aesthetics preferences should be studied. It would also be relevant to analyze how the gameplay approach at large relates to motivations to play, expected outcome gratifications (LaRose 2009), and gameplay behavior style types. For instance, GAIN could be used in player modeling studies that aim to capture patterns in dynamic player-game interaction. By doing so, researchers could investigate how players' game choices correlate with their gameplay choices (Cowley and Charles 2016), and how a player's gameplay preference profile relates to her personality traits and temperament type.

Another important theme for future research would be to investigate how distinctive gameplay activity preferences, for instance, a preference for Aggression, correlates with, e.g., appreciating sensory realism (see Shafer et al. 2014; Ribbens et al. 2016), specific motivations such as immersion (Lin and Peng 2015; Yee 2006), and possible positive and negative media effects, such as aggressive outcomes beyond gameplay situations (e.g., Krcmar et al. 2011; Valadez and Ferguson 2012; Jeong et al. 2012; Zumbach et al. 2015; Greitemeyer 2018).

GAIN should be further developed by exploring how the inventory manages to cover mobile gameplay preferences. Also, it would be crucial to investigate whether GAIN could offer an alternative take on game genres. It is well known that established genres such as 'action games' or 'strategy games' are very general, and game companies and consumers alike have difficulties in identifying which game genres represent specific games the best. Future research should study whether GAIN could help with this problem - which could thus help game companies with marketing and providing new tools for game discovery.

We revealed in this study that there are five facets of gameplay appreciation and that these dimensions are cross-culturally shared since similar factor structures were identified in Finnish, Japanese, and Canadian samples. Players representing different cultural backgrounds evaluated qualities of digital gameplay according to the dimensions we call Aggression, Management, Exploration, Coordination, and Caretaking. We propose that both the 15-item and the 37-GAIN are valid instruments for investigating players' gameplay activity preference factors and modeling player types.

Acknowledgements Open access funding provided by University of Turku (UTU) including Turku University Central Hospital. This research has been supported by Business Finland (864/31/2016) and participating partners, and Academy of Finland (Centre of Excellence in Game Culture Studies).

Open Access This article is distributed under the terms of the Creative Commons Attribution 4.0 International License (http://creativecommons.org/licenses/by/4.0/), which permits unrestricted use, distribution, 
and reproduction in any medium, provided you give appropriate credit to the original author(s) and the source, provide a link to the Creative Commons license, and indicate if changes were made.

\section{Appendix: Factor loadings for the CFA model}

Table 7 Unstandardized and standardized factor loadings for the CFA model of five gameplay activity appreciation factors $(\mathrm{N}=2500)$, as measured with the 15-item GAIN

\begin{tabular}{|c|c|c|c|c|}
\hline \multirow[t]{2}{*}{ Measurement model } & \multicolumn{2}{|l|}{ Estimates } & \multicolumn{2}{|c|}{ Item error variances } \\
\hline & Unstand. & Stand. & Unstand. & Stand \\
\hline Management $\rightarrow$ x1 & 1 (const.) & 0.828 & 0.454 & 0.314 \\
\hline Management $\rightarrow \mathrm{x} 2$ & 1.075 & 0.883 & 0.324 & 0.22 \\
\hline Management $\rightarrow$ x3 & 0.973 & 0.810 & 0.492 & 0.343 \\
\hline Aggression $\rightarrow \mathrm{x} 4$ & 0.897 & 0.789 & 0.606 & 0.378 \\
\hline Aggression $\rightarrow \mathrm{x} 5$ & 1 (const.) & 0.886 & 0.339 & 0.215 \\
\hline Aggression $\rightarrow \mathrm{x} 6$ & 1.013 & 0.861 & 0.445 & 0.314 \\
\hline Exploration $\rightarrow \mathrm{x} 7$ & 1 (const.) & 0.718 & 0.607 & 0.485 \\
\hline Exploration $\rightarrow \mathrm{x} 8$ & 1.266 & 0.830 & 0.467 & 0.311 \\
\hline Exploration $\rightarrow \mathrm{x} 9$ & 1.257 & 0.846 & 0.406 & 0.285 \\
\hline Coordination $\rightarrow \mathrm{x} 10$ & 1.072 & 0.811 & 0.446 & 0.342 \\
\hline Coordination $\rightarrow \mathrm{x} 11$ & 1.027 & 0.829 & 0.449 & 0.313 \\
\hline Coordination $\rightarrow \mathrm{x} 12$ & 1 (const.) & 0.793 & 0.536 & 0.371 \\
\hline Caretaking $\rightarrow \mathrm{x} 13$ & 1 (const.) & 0.743 & 0.73 & 0.447 \\
\hline Caretaking $\rightarrow$ x14 & 1.045 & 0.785 & 0.611 & 0.383 \\
\hline Caretaking $\rightarrow$ x15 & 0.986 & 0.746 & 0.699 & 0.444 \\
\hline \multicolumn{2}{|l|}{ Factor variances } & \multicolumn{2}{|l|}{ Unstand. } & Stand \\
\hline \multicolumn{2}{|l|}{ Management } & \multicolumn{2}{|l|}{0.994} & 1 \\
\hline \multicolumn{2}{|l|}{ Aggression } & \multicolumn{2}{|l|}{1.238} & 1 \\
\hline \multicolumn{2}{|l|}{ Exploration } & \multicolumn{2}{|l|}{0.644} & 1 \\
\hline \multicolumn{2}{|l|}{ Coordination } & \multicolumn{2}{|l|}{0.859} & 1 \\
\hline \multicolumn{2}{|l|}{ Caretaking } & \multicolumn{2}{|l|}{0.902} & 1 \\
\hline \multicolumn{2}{|l|}{ Factor covariances } & \multicolumn{2}{|l|}{ Unstand. } & Stand \\
\hline \multicolumn{2}{|c|}{ Management with aggression } & \multicolumn{2}{|l|}{0.842} & 0.759 \\
\hline \multicolumn{2}{|c|}{ Management with exploration } & \multicolumn{2}{|l|}{0.602} & 0.752 \\
\hline \multicolumn{2}{|c|}{ Management with coordination } & \multicolumn{2}{|l|}{0.598} & 0.647 \\
\hline
\end{tabular}


Table 7 continued

\begin{tabular}{llr}
\hline Factor covariances & Unstand. & Stand. \\
\hline Management with caretaking & 0.516 & 0.545 \\
Aggression with exploration & 0.556 & 0.622 \\
Aggression with coordination & 0.650 & 0.631 \\
Aggression with caretaking & 0.353 & 0.334 \\
Exploration with coordination & 0.461 & 0.619 \\
Exploration with caretaking & 0.413 & 0.543 \\
Coordination with caretaking & 0.559 & 0.636 \\
\hline
\end{tabular}

All factor loadings and covariances are significant on the level of $p<0.001$

RMSEA 0.050, CFI 0.978, TLI 0.970, SRMR 0.029, $D f=80$

\section{References}

Acock, A.C.: Discovering Structural Equation Modeling Using Stata, Revised edn. Stata Press, College Station (2013)

Adams, E.: Fundamentals of Game Design, 3rd edn. New Riders, Berkeley (2014)

Apperley, T.H.: Genre and game studies: toward a critical approach to video game genres. Simul. Gaming 37(1), 6-23 (2006)

Arsenault, D.: Video game genre, evolution and innovation. Eludamos J. Comput. Game Cult. 3(2), 149-176 (2009)

Arsenault, D.: Narratology. In: Wolf, M.J.P., Perron, B. (eds.) The Routledge Companion to Video Game Studies, pp. 475-483. Routledge, New York (2014)

Bartle, R.A.: Hearts, clubs, diamonds, spades: players who suit MUDs. J. Virtual Environ. 1(1), 19 (1996)

Bartle, R.A.: Designing Virtual Worlds. New Riders, Boston (2003)

Bateman, C., Lowenhaupt, R., Nacke, L.E.: Player typology in theory and practice. In: Proceedings of DiGRA 2011 Conference: Think Design Play, pp. 1-13 (2011)

Björk, S., Holopainen, J.: Games and design patterns. In: Salen, K., Zimmerman, E. (eds.) The Game Design Reader. MIT Press, Cambridge (2006)

Brown, T.A.: Confirmatory Factor Analysis for Applied Research, 2nd edn. The Guilford Press, New York (2015)

Chen, L., Chen, G., Wang, F.: Recommender systems based on user reviews: the state of the art. User Model. User Adapt. Interact. 25(2), 99-154 (2015)

Clarke, R.I., Lee, J.H., Clark, N.: Why video game genres fail: a classificatory analysis. Games Cult. 12(5), 445-465 (2015). https://doi.org/10.1177/1555412015591900

Cowley, B., Charles, D.: Behavlets: a method for practical player modelling using psychology-based player traits and domain specific features. User Model. User Adapt. Interact. 26(2), 257-306 (2016). https:// doi.org/10.1007/s11257-016-9170-1

De Schutter, B.: Never too old to play: the appeal of digital games to an older audience. Games Cult. 6(2), 155-170 (2011). https://doi.org/10.1177/1555412010364978

Denisova, A., Guckelsberger, D., Zendle, D.: Challenge in digital games: towards developing a measurement tool. In: CHI17 Extended Abstracts, May 06-11, 2017, Denver, CO, USA ACM 978-1-4503-46566/17/05 (2017). https://doi.org/10.1145/3027063.3053209

Drachen, A., Canossa, A., Yannakakis, G.N.: Player modeling using self-organization in Tomb Raider: underworld. In: Proceedings of the IEEE symposium on computational intelligence and games (2009)

Farrell, A.M.: Insufficient discriminant validity: a comment on Bove, Pervan, Beatty and Shiu (2009). J. Bus. Res. 63(3), 324-327 (2009)

Fornell, C., Larcker, D.F.: Evaluating structural equation models with unobservable variables and measurement error. J. Mark. Res. 18(1), 39-50 (1981)

Greenberg, B.S., Sherry, J., Lachlan, K., Lucas, K., Holmstrom, A.: Orientations to video games among gender and age groups. Simul. Gaming 41(2), 238-259 (2010). https://doi.org/10.1177/ 1046878108319930 
Greitemeyer, T.: The spreading impact of playing violent video games on aggression. Comput. Hum. Behav. 80, 216-219 (2018)

Hamari, J., Tuunanen, J.: Player types: a meta-synthesis. Trans. Dig. Games Res. Assoc. 1(2), 29-53 (2014)

Harrington, D.: Confirmatory Factor Anal. Oxford University Press, Oxford (2009)

Hartmann, T., Klimmt, C.: The influence of personality factors on computer game choice. In: Vorderer, P., Bryant, J. (eds.) Playing Video Games. Motives, Responses, and Consequences, pp. 115-132. Routledge, New York (2006)

Henson, R.K., Roberts, J.K.: Use of exploratory factor analysis in published research: common errors and some comment on improved practice. Educ. Psychol. Meas. 66, 393-416 (2006)

Hu, L.T., Bentler, P.M.: Cutoff criteria for fit indexes in covariance structure analysis: conventional criteria versus new alternatives. Struct. Equ. Model. Multidiscip. J. 6(1), 1-55 (1999)

Hunicke, R., LeBlanc, M., Zubek, R.: MDA: a formal approach to game design and game research. In: Proceedings of AAAI workshop on Challenges in Game. AAAI Press (2004)

Jeong, J., Biocca, F.A., Bohil, C.J.: Sensory realism and mediated aggression in video games. Comput. Hum. Behav. 28(5), 1840-1848 (2012)

Jöckel, S., Dogruel, L.: The right game: video game choice of children and adolescents. In: Fromme, J., Unger, A. (eds.) Computer Games and New Media Cultures, pp. 343-356. Springer, Dordrecht (2012)

Juul, J.: Half-Real: Video Games Between Real Rules and Fictional Worlds. The MIT Press, Cambridge (2005)

Juul, J.: Genre in video games (and why we don't talk [more] about it). A blog entry in the blog The Ludologist (2014). https://www.jesperjuul.net/ludologist/2014/12/22/genre-in-video-games-and-why-wedont-talk-about-it/. Accessed 30 Dec 2017

Kaptelinin, V., Nardi, B.A.: Acting with Technology: Activity Theory and Interaction Design. The MIT Press, Cambridge (2006)

Kirkpatrick, G.: Constitutive tensions of gamings field: UK gaming magazines and the formation of gaming culture 1981-1995. Game Studies 12(1) (2012)

Kline, R.B.: Principles and Practice of Structural Equation Modeling, 3rd edn. The Guilford Press, New York (2010)

Krcmar, M., Strizhakova, Y.: Uses and gratifications as media choice. In: Hartmann, T. (ed.) Media Choice: A Theoretical and Empirical Overview, pp. 53-69. Routledge, New York (2009)

Krcmar, M., Farrar, K., McGloin, R.: The effects of video game realism on attention, retention and aggressive outcomes. Comput. Hum. Behav. 27(1), 432-439 (2011)

Landay, L.: Interactivity. In: Wolf, M.J.P., Perron, B. (eds.) The Routledge Companion to Video Game Studies, pp. 173-184. Routledge, New York (2014)

LaRose, R.: Social cognitive theories of media selection. In: Hartmann, T. (ed.) Media Choice: A Theoretical and Empirical Overview, pp. 10-31. Routledge, New York (2009)

LeBlanc, M.: Tools for creating dramatic game dynamics. In: Salen, K., Zimmerman, E. (eds.) The Game Design Reader: A Rules of Play Anthology, pp. 438-459. The MIT Press, Cambridge (2004)

Leino, O.T.: Untangling gameplay: an account of experience, activity and materiality within computer game play. In: Sageng, J.R., Fossheim, H.J., MandtLarsen, T. (eds.) The Philosophy of Computer Games, Vol. 7 of Philosophy of Engineering and Technology, pp. 57-75. Springer, Dordrecht (2012)

Lin, J., Peng, W.: The contributions of perceived graphic and enactive realism to enjoyment and engagement in active video games. Int. J. Technol. Hum. Interact. 11(3), 121-137 (2015). https://doi.org/10.4018/ ijthi.2015070101

Lucas, K., Sherry, J.L.: Sex differences in video game play: a communication-based explanation. Commun. Res. 31, 499-523 (2004)

Marsh, H.W., Hau, K.T., Wen, Z.: In search of golden rules: comment on hypothesis-testing approaches to setting cutoff values for fit indexes and dangers in overgeneralizing Hu and Bentler's (1999) findings. Struct. Equ. Model. 11(3), 320-341 (2004)

Matsunaga, M.: How to factor-analyze your data right: do's, don'ts, and how-to's. Int. J. Psychol. Res. 3(1), 97-110 (2010)

Meade, A.W., Craig, S.B.: Identifying careless responses in survey data. Psychol. Methods 17(3), 437-455 (2012)

Mulligan, J., Patrovsky, B.: Developing Online Games: An Insider's Guide. New Riders, San Francisco (2003)

Neogames: The game industry of Finland report 2016 (2016). http://www.neogames.fi/wp-content/uploads/ 2017/04/Finnish-Game-Industry-Report-2016_web_070529.pdf. Retrieved 22 Dec 2017 
Peterson, R.A.: Problems in comparative research: the example of omnivorousness. Poetics 33(5-6), 257$282(2005)$

Prior, M.: Post-broadcast Democracy: How Media Choice Increases Inequality in Political Involvement and Polarizes Elections. Cambridge University Press, Cambridge (2007)

Przybylski, A., Rigby, C.S., Ryan, R.M.: A motivational model of video game engagement. Rev. Gen. Psychol. 14(2), 154-166 (2010). https://doi.org/10.1037/a0019440

Quandt, T., Grüninger, H., Wimmer, J.: The grey haired gaming generation: findings from an explorative interview study on older computer gamers. Games Cult. 4, 27-46 (2009). https://doi.org/10.1177/ 1555412008325480

Ribbens, W., Malliet, S., van Eck, R., Larkin, D.: Perceived realism in shooting games: towards scale validation. Comput. Hum. Behav. 64, 308-318 (2016). https://doi.org/10.1016/j.chb.2016.06.055

Rubin, A.M.: The uses-and-gratifications perspective of media effects. In: Bryant, J., Zillmann, D. (eds.) Media Effects: Advances in Theory and Research, pp. 525-548. Erlbaum, Mahwah (2002)

Ruggiero, T.E.: Uses and gratifications theory in the 21st century. Mass Commun. Soc. 3, 3-37 (2000)

Russell, D.W.: In search of underlying dimensions: the use (and abuse) of factor analysis in personality and social psychology bulletin. Personal. Soc. Psychol. Bull. 28, 1629-1646 (2002)

Scharkow, M., Festl, R., Vogelgesand, J., Quandt, T.: Beyond the "core-gamer": genre preferences and gratifications in computer games. Comput. Hum. Behav. 44, 293-298 (2015)

Scherer, H., Naab, T.: Money does matter. In: Hartmann, T. (ed.) Media Choice. A Theoretical and Empirical Overview, pp. 70-83. Routledge, New York (2009)

Schreiber, J.B., Nora, A., Stage, F.K., Barlow, E.A., King, J.: Reporting structural equation modeling and confirmatory factor analysis results: a review. J. Educ. Res. 99, 323-337 (2006)

Shafer, D.M., Carbonara, C.P., Popova, L.: Controller required? the impact of natural mapping on interactivity, realism, presence, and enjoyment in motion-based video games. Presence Teleoperators Virtual Environ. 23(3), 267-283 (2014)

Sherry, J.L.: Flow and media enjoyment. Commun. Theory 14(4), 328-347 (2004)

Sherry, J.L., Lucas, K., Greenberg, B.S., Lachlan, K.: Video game uses and gratifications as predictors of use and game preference. In: Vorderer, P., Bryant, J. (eds.) Playing Video Games. Motives, Responses, and Consequences, pp. 213-224. Routledge, New York (2006)

Sicart, M.: Defining game mechanics. Game Stud. 8(2) (2009)

Terlecki, M., Brown, J., Harner-Steciw, L., Irvin-Hannum, J., Marchetto-Ryan, N., Ruhl, L., Wiggins, J.: Sex differences and similarities in video game experience, preferences, and self-efficacy: implications for the gaming industry. Curr. Psychol. 30(1), 22-33 (2011). https://doi.org/10.1007/s12144-010-90955

Tondello, G.F., Wehbe, R.R., Orji, R., Ribeiro, G., Nacke, L.E.: A framework and taxonomy of videogame playing preferences. In: Proceedings of the Annual Symposium on Computer-Human Interaction in Play, pp. 329-340 (2017). https://doi.org/10.1145/3116595.3116629

Tseng, F.C.: Segmenting online gamers by motivation. Expert Syst. Appl. 38, 7693-7697 (2010). https:// doi.org/10.1016/j.eswa.2010.12.142

Vahlo, J.: An enactive account of the autonomy of videogame gameplay. Game Stud. 17(1) (2017)

Vahlo, J.: In Gameplay. The invariant structures and varieties of the video game gameplay experience. Academic Dissertation. Ph.D. thesis, University of Turku, Turku (2018)

Vahlo, J., Koponen, A.: Player personas and game choice. In: Lee, N. (ed.) Encyclopedia of Computer Graphics and Games. Springer, Cham (2018)

Vahlo, J., Kaakinen, J., Holm, S., Koponen, A.: Digital game dynamics preferences and player types. J. Comput. Med. Commun. 22(2), 88-103 (2017). https://doi.org/10.1111/jcc4.12181

Valadez, J.J., Ferguson, C.J.: Just a game after all: violent video game exposure and time spent playing effects on hostile feelings, depression, and visuospatial cognition. Comput. Hum. Behav. 28(2), 608616 (2012). https://doi.org/10.1016/j.chb.2011.11.006

Vorderer, P., Klimmt, C., Ritterfeld, U.: Enjoyment: at the heart of media entertainment. Commun. Theory 14(4), 388-408 (2004)

von Salisch, M., Vogelgesand, J., Kristen, A., Oppl, C.: Preference for violent electronic games and aggressive behavior among children: the beginning of the downward spiral? Media Psychol. 14(3), 233-258 (2011). https://doi.org/10.1080/15213269.2011.596468

Webster, J.G.: The role of structure in media choice: a theoretical and empirical overview. In: Hartmann, T. (ed.) Media Choice: A Theoretical and Empirical Overview, pp. 221-233. Routledge, New York (2009) 
Webster, J.G.: The duality of media: a structurational theory of public attention. Commun. Theory 21, 43-66 (2011). https://doi.org/10.1111/j.1468-2885.2010.01375.x

Webster, J.G.: The Marketplace of Attention. How Audiences Take Shape in a Digital Age. The MIT Press, Cambridge (2014)

Webster, J.G., Ksiasek, T.B.: The dynamics of audience fragmentation: public attention in an age of digital media. J. Commun. 62, 39-56 (2012)

Webster, J.G., Wakshlag, J.J.: A theory of television program choice. Commun. Res. 10(4), 430-446 (1983)

Wolling, J.: The effect of subjective quality assessments on media selection. In: Hartmann, T. (ed.) Media Choice: A Theoretical and Empirical Overview, pp. 84-101. Routledge, New York (2009)

Yannakakis, G.N., Spronck, P., Loiacono, D., André, E.: Player modeling. In: Artificial and Computational Intelligence in Games. Dagstuhl Seminar 12191., pp. 45-55. Dagstuhl Publishing, Saarbrücken (2013)

Yee, N.: Motivations for play in online games. J. CyberPsychol. Behav. 9, 772-775 (2006)

Yee, N., Ducheneaut, N., Nelson, L.: Online gaming motivations scale: development and validation. In: Proceedings of the SIGCHI Conference on Human Factors in Computing Systems, pp. 2803-2806 (2012). https://doi.org/10.1145/2207676.2208681

Youn, S.: Program type preference and program choice in a multichannel situation. J. Broadcast. Electron. Media 38(4), 465-475 (1994)

Zait, A., Bertea, P.: Methods for testing discriminant validity. Manag. Mark. IX(2), 217-224 (2011)

Zumbach, J., Seitz, C., Bluemke, M.: Impact of violent video game realism on the self-concept of aggressiveness assessed with explicit and implicit measures. Comput. Hum. Behav. 53, 278-288 (2015). https://doi.org/10.1016/j.chb.2015.07.018

Jukka Vahlo is a Postdoctoral Researcher at Centre of Excellence in Game Culture Studies at Tampere University. He is also working as a Research Manager at School of Economics, University of Turku. His current research interests focus on gameplay experience, player personas and player profiling, media choice, and game recommender systems.

Jouni Smed holds a doctorate in Computer Science and acts a Senior Lecturer and Adjunct Professor at University of Turku, Finland. For the past twenty years, his research interests have focused on various areas of game development: from code tweaking to software processes and from simple puzzles to multisite game development.

Aki Koponen is as a Research Director in the Centre for Collaborative Research at Turku School of Economics, University of Turku. His research activities focus currently on digital gaming, gamer analytics, and digitalization and disruption of industries. He loves skiing, gaming and ska punk. 